\title{
Köprülerin Yapısal Analizinde Hareketli Yük Dağıtma Katsayıları Etkisinin İncelenmesi
}

\author{
Fatma ÜLKER PEKER ${ }^{1 *}$,Ragip İNCE ${ }^{2}$ \\ ${ }^{I}$ Malatya Turgut Özal Üniversitesi, Mühendislik ve Doğa Bilimleri Fakültesi, İnşaat Müh. Bölümü, Malatya \\ ${ }^{2}$ Fırat Üniversitesi, Mühendislik Fakültesi, İnşaat Mühendisliği Bölümü, Elazı̆̆ \\ (ORCID: 0000-0002-0805-4367) (ORCID: 0000-0002-9837-8284)
}

\begin{abstract}
$\ddot{\mathbf{O} z}$
Bu çalışmada AASHTO-LRFD Köprü Şartnamesinde uygulama ve hesap özellikleri verilen hareketli yük dağıtma katsayılarının (LLDF) köprülerin analizinde kullanılması araştıılmıştır. Bu amaçla, üç açıklıklı 30-30-30 m ve 3350-38 m köprülerin LLDF hesaplamaları AASHTO Şartnamesine göre yapılmıştır. Bu köprüler yaklaşık analiz yöntemi olan Çizgisel-Kiriş yöntemiyle analiz edilmiştir ve hesaplanan LLDF katsayıları analizde kullanılmıştır. 30-30-30 m köprünün SAP2000 programıyla ve 33-50-38 m köprünün CSiBridge programıyla analizi yapılmıştır. $\mathrm{Bu}$ programlarla yapılan analizde LLDF katsayıları program tarafindan otomatik olarak hesaplamalara katılmaktadır. Yapılan çalışma sonucunda Çizgisel-Kiriş yöntemiyle analizden elde edilen sonuçların, hassas ve kesin analiz yapan SAP2000 ve CSiBridge programlarıyla elde edilen sonuçlara çok yakın olduğu görülmüştür. Böylece, AASHTO Tasarım Şartnamesi’ne göre LLDF hesaplamalarının yapısal analizde kullanımının doğruluğu ve uygunluğu ortaya konulmuştur.
\end{abstract}

Anahtar kelimeler: Çelik köprü, köprü analizi, çizgisel-kiriş analizi, LLDF.

\section{Investigation of Live Load Distribution Factors Effect in Structural Analysis of Bridges}

\begin{abstract}
In this study, the use of live load distribution factors (LLDF) that application and calculation properties are defined in the AASHTO Bridge Specification, in the analysis of bridges is investigated. For this purpose, LLDF calculations of three spans of 30-30-30 m and 33-50-38 m bridges is made according to AASHTO Specification. These bridges are analyzed by Line-Girder method and calculated LLDF coefficients are used in the analysis. The 30-30-30 m bridge is analyzed by SAP2000 program and the 33-50-38 m bridge is analyzed by CSiBridge program. In the analysis made with these programs, LLDF coefficients are automatically included in the calculations by the program. As a result of the study, it was seen that the results obtained from the Linear-Girder analysis were very close to the results obtained with the SAP2000 and CSiBridge programs which perform precise and exact analysis. Thus, the accuracy and appropriateness of the use of LLDF calculations in structural analysis according to AASHTO Design Specification have been demonstrated.
\end{abstract}

Keywords: Steel bridge, bridge analysis, line-girder analysis, LLDF.

\section{Giriş}

Kiriş dağıtma katsayısı veya tekerlek yükü dağıtma katsayısı olarak da adlandırılan hareketli yük dağıtma katsayısı (LLDF), bir köprü sisteminin karmaşık üç boyutlu davranışını tek boyutlu bir problemde basitleştirmek için köprü mühendisleri tarafından kullanılmaktadır. Köprülerin analiz ve tasarımı araştırılırken, açıklıkta pozitif gerilmenin, mesnetlerde maksimum negatif gerilmenin ve köprüdeki deplasmanların belirlenmesi önemlidir. Bunun için bir ve çok şerit yüklü durumlarda Hareketli Yük Dağıtma Katsayısı (LLDF)'nin bilinmesi gerekmektedir [1-3].

\footnotetext{
*Sorumlu yazar: fatma.peker@ozal.edu.tr

Geliş Tarihi: 08.10.2019, Kabul Tarihi: 19.03.2020
} 
LLDF hesaplaması AASHTO Köprü Tasarım Şartnamesi’ne göre yapılır. Bu hesaplamalar köprü konfigürasyonuna göre değişmekte ve köprünün yapısal özelliklerine bağlı parametreler kullanılmaktadır. Köprüde maksimum yüklemeler iç kirişlerde yaratıldığından bu çalışmada LLDF katsayılarının hesabı iç kirişler için yapılmıştır $[1,2]$.

Köprülerde hareketli yük dağıtma katsayıları (LLDF) nın incelenmesi ile ilgi yapılan çalışmaları incelediğimizde; Dicleli ve Erhan yaptıkları çalışmada [4], integral kenar ayaklı köprü hareketli yük dağıtımına zemin ve alt yapı özelliklerinin etkisini incelemişlerdir. Erhan ve Dicleli bir başka çalışmada [5], integral köprü alt yapıları için hareketli yük dağıtıma eşitliklerini araştırmışlardır. Yine Dicleli ve Erhan [6] yaptıkları çalışmada, tek açıklıklı öngerilmeli beton kenar ayaklı köprü kirişleri için hareketli yük dağıtma formüllerini geliştirmişlerdir. Erhan ve Dicleli, integral köprü alt yapılarında AASHTO LRFD hareketli yük dağıtma eşitliklerinin uygulanabilirliğinin araştırılmasını kaynak [7]'de gerçekleştirmişlerdir. Dicleli ve Erhan [8], integral kenar ayaklı köprü kirişlerinde hareketli yük dağılımında üst yapı-kenar ayak sürekliliğine olan etkiyi araştırmışlardır. Yalçın ve Dicleli integral kenar ayaklı ve basit mesnetli köprü kirişlerinde hareketli yük dağıtımı üzerine kiriş sayısının etkisi ile ilgili karşılaştırmalı bir çalışma yapmışlardır [9]. Yalçın yaptığı çalışmada [10], verevli integral köprü kirişleri ile verevli basit mesnetli köprü kirişlerinde hareketli yükün dağıtılmasını karşılaştırmalı olarak incelemiştir. Kim ve ark. [11], askeri araç geçiş köprülerinin yük konfigürasyonu ve yanal yük dağıtılmasıyla ilgili bir çalışma yapmışlardır. Fanous ve ark. [12], yapıştırılmış lamine kereste kirişli köprülerde hareketli yük dağıtma katsayılarının geliştirilmesi üzerine bir araştırma yapmışlardır. Zou ve ark. [3], ortotropik köprü tabliyelerinde yük dağıtma katsayılarının ardışı çözümle değerlendirmesini incelemişlerdir. Kalaycı ve ark.[13], ABD'de Vermont Eyaletinde integral kenar ayaklı köprülerde yük testi ve modellenmesi ile ilgili bir çalışma yapmışlardır. Hodson ve ark. [14], yaptıkları çalışmada ardgermeli kutu kirişli köprülerde hareketli yüklerin analizini incelemişlerdir. Hodson ve ark. [15], yaptıkları çalışmada ardgermeli kutu kirişli bir köprünün yük derecelendirmesini ve hareketli yük testi karşılaştırmasını yapmışlardır. Suksawang ve ark. [16], I-kiriş köprüler için kayma hareketli yük dağıtma katsayısı eşitliklerinin doğrulanması üzerine bir çalışma yapmışlardır. Mohseni ve ark. [17], çok hücreli kutu kirişli köprülerde ara diyaframın yanal yük dağıtma katsayısı üzerine etkisini incelemişlerdir. Mohseni ve ark. [18], hareketli yüklere maruz eğrisel sürekli çok hücreli kutu kirişli köprülerin orta ayaklarında hareketli yük dağıtma katsayılarının etkisini incelemiş̧lerdir. Yan ve ark. [19], rastgele araç yükleme konumundan dolayı hareketli yük dağıtma katsayısının olasılıksal dağılımını göz önüne alarak mevcut öngerilmeli beton köprülerin değerlendirilmesini yapmışlardır. Thakuria ve Talukdar [20], prekast I-kiriş köprülerin kayma hareketli yük dağıtma katsayılarını incelemişlerdir. Miranbeigi ve Maleki [21], kirişli köprülerde tank yüklemesi için hareketli yük dağıtma katsayını incelemişlerdir. Choi ve ark. [22], araç yüklemesi altında beton kutu kirişli köprülerde hareketli yük dağıtma katsayısı denkleminin geliştirilmesi üzerine bir çalışma yapmışlardır.

$\mathrm{Bu}$ çalışmada köprü kirişlerinde hareketli yük dağıtma katsayısının etkisi araştırılmıştır. Çalışmada önce, köprülerde hareketli yük dağıtma katsayılarının önemi üzerinde durulmuş ve bu konuda yapılmış önemli çalışmalar bir literatür araştırmasıyla verilmiştir. Çalışmanın ikinci kısmında, yük etkisinde en çok zorlanan köprü iç kirişlerinin AASHTO Köprü Tasarım Şartnamesine göre hareketli yük dağıtma katsayılarının hesaplanması açıklanmıştır. Araştırmanın üçüncü ve dördüncü bölümlerinde, örnek olarak seçilen 30-30-30 m ve 33-50-38 m üç açıklıklı köprülerin LLDF katsayıları hesaplanmıştır. Hesaplanan bu LLDF katsayıları Çizgisel-Kiriş yöntemi ile yapısal analiz çözümünde kullanılmıştır. 3D kesin çözüm yapan SAP2000 Bridge ve CSiBridge paket programları ile de köprülerin analizi yapılmış ve elde edilen sonuçlar Çizgisel-Kiriş analizi ile karşılaştırılmıştır.

\section{Materyal ve Metot}

\section{1. İç Kirişlerde Moment Dağılımı}

AASHTO Şartnamesinin Hareketli Yük Dağıtma Katsayısı LLDF ile ilgili yaklaşımı aşağıda yer verilen eşitliklerle hesaplanmaktır.

Bir şerit yüklü tasarım durumunda hareketli yük dağıtma katsayısı: 


$$
L L D F_{M, I n t}=0.06+\left(\frac{S}{4300}\right)^{0.4}\left(\frac{S}{L}\right)^{0.3}\left(\frac{K_{g}}{L t_{s}^{3}}\right)^{0.1}
$$

İki veya daha çok şerit yüklü tasarım durumunda hareketli yük dağıtma katsayısı:

$L L D F_{M, I n t}=0.075+\left(\frac{S}{2900}\right)^{0.6}\left(\frac{S}{L}\right)^{0.2}\left(\frac{K_{g}}{L t_{s}^{3}}\right)^{0.1}$

Yukarıda verilen eşitlikler SI birim sistemiyle yazılmıştır. Bu bağıntılarda; S, kiriş aralı̆̆ı, L, kiriş açılı̆ğ $t_{s}$, beton plak kalınlığı, $K_{g}$, boyuna rijitlik parametresini ifade etmektedir. Ayrıca kiriş sayısı $\mathrm{Nb}>4$ olması gerekmektedir. En az kiriş sayısı $\mathrm{Nb}=4$ olmakla birlikte, tabliye düzenlenmesinde pratiklik bakımından $\mathrm{Nb}=5$ seçilebilmektedir.

SAP2000 ve CSiBridge programlarında köprü analizi tamamlandıktan sonra "Design $\rightarrow$ Superstructure Design $\rightarrow$ Design Requests" sekmesi altında tasarım için tanımlamalar yapılmaktadır. Açılan pencerede, hareketli yükün kirişlere dağılımı için dört yöntem verilmiştir. Bu yöntemlerden, "Kullanıcının Belirlediği Katsayıları Kullan" ile verilen iç ve dıș kirișler için moment katsayıları default değerlerdir. Yine burada "Şartnamenin Belirlediği Katsayıları Kullan" ile ikinci bir yöntem de seçilebilmektedir.

\section{Bulgular ve Tartışma}

\section{1. Üç Açıklıklı 30-30-30 m Köprünün LLDF Hareketli Yük Dağıtma Katsayılarının Hesaplanması}

Uygun bir LLDF katsayısı belirlemek amac1yla, SAP2000 programında "Quick Bridge" ile yaratılan $3 * 30=90 \mathrm{~m}$ uzunluğundaki köprünün "Bridge Wizard" altında çözülen köprünün enkesit özelliklerinden yararlanılmıştır. Tipik köprü ve kiriş enkesitleri Şekil 1'de gösterilmektedir. Kenar ayaklar K.Ayak1 sabit, K.Ayak4 hareketli, orta ayaklar O.Ayak2 ve O.Ayak3 hareketli alınmıştır.

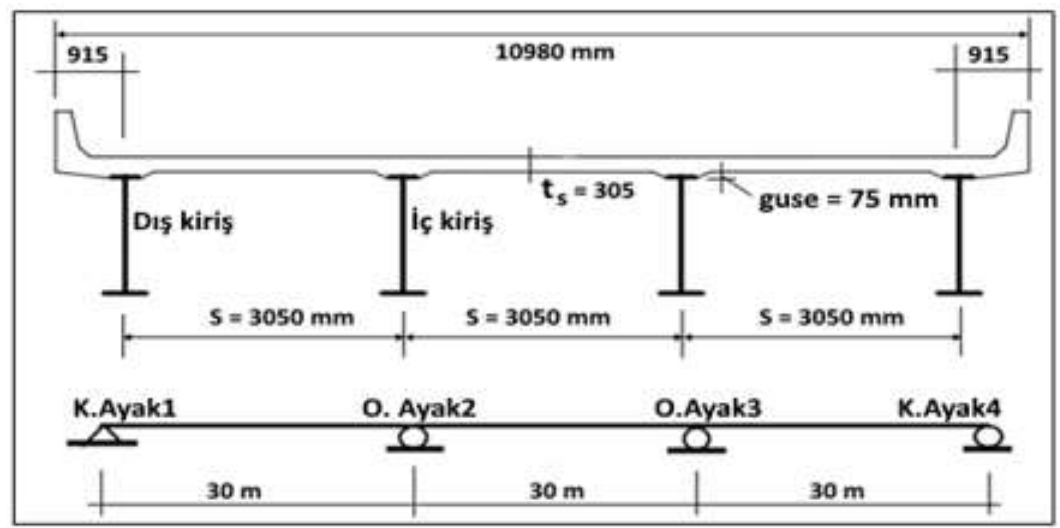

(a)

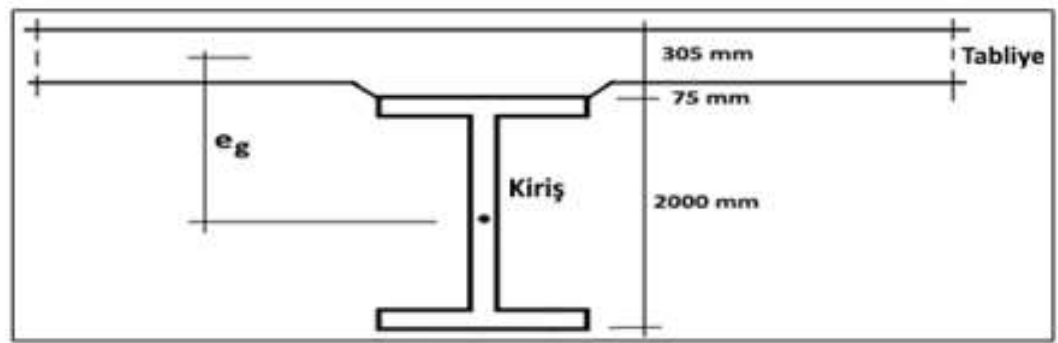

(b)

Şekil 1. Üç-açıklıklı çelik I-Kiriş köprü (a) Köprünün enkesit ve boykesitleri (b) Köprünün kiriş enkesiti. 
Köprü ile ilgili teknik bilgiler:

- $\quad S=3050 \mathrm{~mm} ; L=30000 \mathrm{~mm} ; \quad t_{s}=305 \mathrm{~mm}$;

- Beton (4000Psi) basınç dayanımı: $f_{c}=27.579 \mathrm{MPa}$;

- Beton elastisite modülü: $E_{c}=4734 \sqrt{f_{c}}=24861 \mathrm{MPa}$;

- Çelik elastisite modülü: $E_{s}=200000 \mathrm{MPa}$;

- $\quad$ Elastisite modülleri oranı: $n=\frac{200000}{24861} \cong 8.0$

olarak verilmiştir. Kiriş enkesit alanı ve atalet momenti, SAP2000 programından, $A_{g}=62380 \mathrm{~mm}^{2} ; I_{g}=$ $3.902 * 10^{10} \mathrm{~mm}^{4}$ olarak alınmıştır.

Kiriş eksantritesi Eş. 3, Rijitlik parametresi ise Eş. 4 ile hesaplanmaktadır:

$$
\begin{aligned}
e_{g} & =\frac{2000}{2}+75+\frac{305}{2}=1227.5 \mathrm{~mm} \\
K_{g} & =n\left(I+A e_{g}^{2}\right) \\
K_{g} & =8.0 *\left(3.902 * 10^{10}+62380 * 1227.5^{2}\right)=1.064 * 10^{12} \mathrm{~mm}^{4}
\end{aligned}
$$

Bir şerit yüklü tasarım durumunda hareketli yük dağıtma katsayısı:

$$
L L D F_{M, I n t}=0.06+\left(\frac{3050}{4300}\right)^{0.4}\left(\frac{3050}{30000}\right)^{0.3}\left(\frac{1.064 * 10^{12}}{30000 * 305^{3}}\right)^{0.1}=0.509 \text { Şerit } / \text { Kiriş }
$$

İki veya daha çok şerit yüklü tasarım durumunda hareketli yük dağıtma katsayısı:

$L L D F_{M, I n t}=0.075+\left(\frac{3050}{2900}\right)^{0.6}\left(\frac{3050}{30000}\right)^{0.2}\left(\frac{1.064 * 10^{12}}{30000 * 305^{3}}\right)^{0.1}=0.742$ Şerit $/$ Kiriş

Eşitlik 5 ve 6'daki $\left(\frac{K_{g}}{12 L t_{s}^{3}}\right)^{0.1}$ terimi 1.02257 olarak hesaplanmaktadır, bu da ön tasarımda 1.0 olarak alınmasının uygun bir yaklaşım olduğunu göstermektedir. Köprü hareketli yük dağıtma katsayısı LLDF'nin hesaplanması ayrınt1lı olarak Tablo 1'de verilmektedir.

Bir yüklü şerit ve çok yüklü şerit için hesaplanan LLDF katsayılarından en büyük olan değer tasarımda göz önüne alınmaktadır. Örneğin, birinci açıklık için, $L L D F_{M, I n t}=0.509$ Şerit $/$ Kiriş ve $L L D F_{M, \text { Int }}=0.742$ Şerit $/$ Kiriş değerlerinden, tasarımda kullanılacak katsay1; $L L D F_{M, I n t}=$ 0.742 Şerit/Kiriş değeri seçilir. Tasarımda göz önüne alınacak hareketli yük eğilme momentleri; en elverişsiz yüklemeler altında elde edilen Envelope (ZARF) momentlerinin, LLDF katsayısıyla çarpımı Eş. 7'de yer verilen ifade ile elde edilmektedir.

$$
\max M=(L L D F) *\left(M_{Z A R F}\right)
$$

Kesit özellikleri Şekil 1' de verilen üç açıklıklı 30-30-30 m köprü SAP2000 V14.2 de mevcut olan "Bridge Wizard" ile modellenmiş (Şekil 2) ve analiz edilmiştir. Burada SAP2000 Bridge çözümünden birinci açıklık için iç kirişte HL-93K araç yüklemesinden dolayı pozitif hareketli yük momenti, $\operatorname{maxM}_{1}=1882.82 \mathrm{KNm}$ olarak bulunmuştur. SAP2000 Bridge ile elde edilen $\mathrm{M}_{\text {ZARF }}$ momentine LLDF katsayısı program tarafindan otomatik olarak katılmıştır. Aynı köprünün tesir çizgileri yöntemi ile analizi yapılmış ve birinci açıklıkta açıklık ortasında HL-93K araç yüklemesinden dolayı pozitif hareketli yük momenti, hareketli yük dağıtma katsayısı LLDF göz önüne alındığında $\operatorname{maxM}_{1}=1638 \mathrm{KNm}$ elde edilmiştir [2]. 
Tablo 1. Üç-açıklıklı 30-30-30 m köprünün LLDF hareketli yük dağıtma katsayıları

\begin{tabular}{|c|c|c|c|c|c|}
\hline \multicolumn{6}{|c|}{3 Açıklıklı 30-30-30 m Köprünün Hareketli Yük Dağıtma katsayılarının; LLDF Hesabı } \\
\hline \multicolumn{6}{|c|}{$\begin{array}{l}\text { Hesaplarda kullanılan değerler, köprünün CSiBridge çözümünden aktarılmıştır. (Birim: SI birim sistemi) } \\
\text { Açıklıklarda ve mesnetlerde aynı kesit kullanılmıştır. }\end{array}$} \\
\hline $\begin{aligned} & S= 3050 \\
& L 1= 30000 \\
& L 2= 30000 \\
& L 3= 30000 \\
& \text { 1. iç mesnet } L=30000 \\
& \text { 2. iç mesnet } L=30000\end{aligned}$ & $\begin{array}{l}\mathrm{mm} \\
\mathrm{mm} \\
\mathrm{mm} \\
\mathrm{mm} \\
\mathrm{mm} \\
\mathrm{mm}\end{array}$ & $\begin{array}{rlr}\text { Açıklıkta eg}=1227.5 & \mathrm{~mm} \\
\text { mesnette eg}=1227.5 & \mathrm{~mm} \\
\mathrm{ts} & =305 & \mathrm{~mm} \\
\text { Es/Ec oranı } \mathrm{n}=8 & \\
\text { guse }=75 & \mathrm{~mm} \\
\text { kesit1 } \mathrm{h}=2000 & \mathrm{~mm} \\
\text { kesit2 } \mathrm{h}=2000 & \mathrm{~mm}\end{array}$ & $\begin{aligned} \mathrm{A} 1 & =62380 \\
\mathrm{~A} 2 & =62380 \\
\mathrm{I} 1 & =39020000000 \\
\mathrm{I} & =39020000000 \\
\mathrm{Kg} 1 & =1.06409 \mathrm{E}+12 \\
\mathrm{Kg} 2 & =1.06409 \mathrm{E}+12\end{aligned}$ & $\begin{array}{l}\mathrm{mm}^{2} \\
\mathrm{~mm}^{2} \\
\mathrm{~mm}^{4} \\
\mathrm{~mm}^{4} \\
\mathrm{~mm}^{4} \\
\mathrm{~mm}^{4}\end{array}$ & \\
\hline \multicolumn{3}{|c|}{ "Bir yüklü şerit için iç kirişlerde LLDF hesabı } & \multicolumn{3}{|c|}{ Ç̧ok yüklü şerit için iç kirişlerde LLDF hesabı } \\
\hline 1. açıklıkta LLDF= & 0.509 & Şerit/Kiriş & 1. açıklıkta LLDF= & 0.742 & Şerit/Kiriş \\
\hline 2. açıklıkta LLDF= & 0.509 & Şerit/Kiriş & 2. açıklıkta LLDF= & 0.742 & Şerit/Kiriş \\
\hline 3. açıklıkta LLDF= & 0.509 & Şerit/Kiriş & 3. açıklıkta LLDF= & 0.742 & Şerit/Kiriş \\
\hline 1. mesnette LLDF= & 0.509 & Şerit/Kiriş & 1. mesnette LLDF= & 0.742 & Şerit/Kiriş \\
\hline 2. mesnette LLDF= & 0.509 & Şerit/Kiriş & 2. mesnette LLDF= & 0.742 & Şerit/Kiriş \\
\hline
\end{tabular}

Tesir çizgileri yöntemiyle SAP2000 Bridge sonuçları karşılaştırıldığında, iç kirişin açıklık ortası momentinin \%15 daha büyük olduğu sonucu ortaya çıkmıştır. Momentlerin hesaplanmasında, hareketli yük dağıtma katsayısı LLDF’nin gerçek değerleri kullanıldığında daha hassas sonuçların elde edildiği görülmüştür [2].

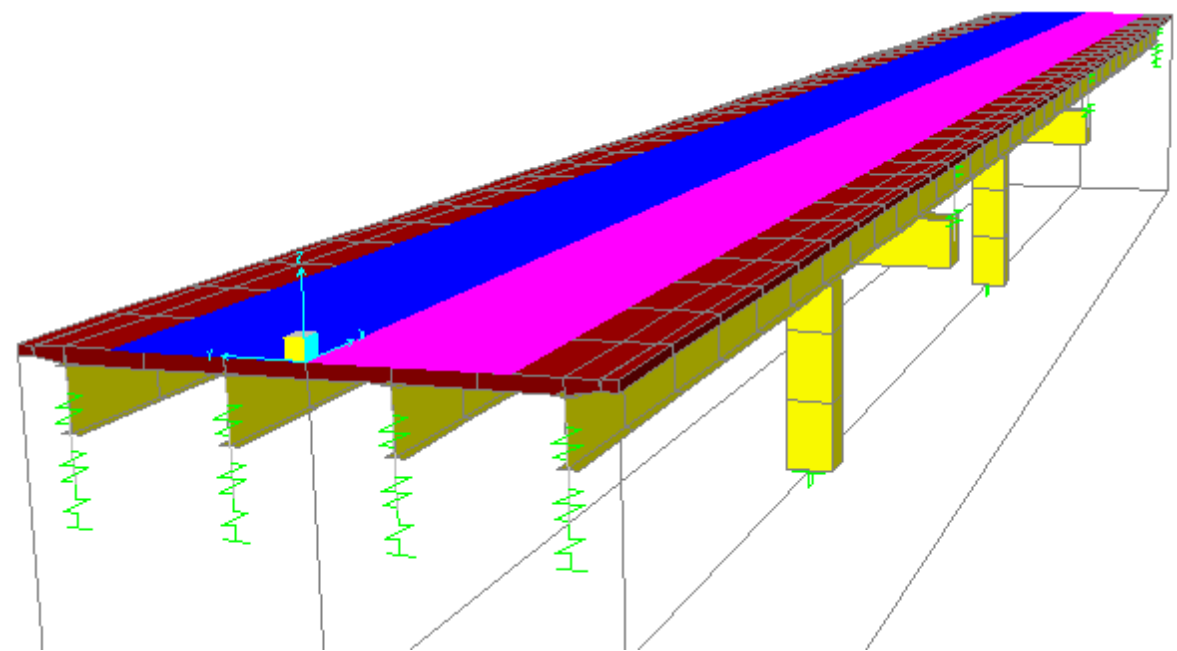

Şekil 2. Üç-açıklıklı sürekli köprü kirişin SAP2000 Bridge Wizard ile modellenmesi

\section{2. Üç Açıklıkı 33-50-38 m Köprünün LLDF Hareketli Yük Dağıtma Katsayılarının Hesaplanmasi}

Şekil 3'te gösterilen köprü sisteminde, farklı iki kesit kullanılarak prizmatik olmayan açıklıklar elde edilmiștir. Sistemde 2 kenar 3 te iç olmak üzere 5 adet kiriș eșit aralıklarla yerleştirilmiștir. Kenar ayaklar K.Ayakl ve K.Ayak4 hareketli, orta ayaklar O.Ayak2 ve O.Ayak3 ise sabit alınmıştır. Bu köprüde AASHTO LRFD şartnamesine göre yapılan bu hesaplamaların geçerliliği Tablo 2' de gösterilen sınırlamalarla kontrol edilmektedir. Şekil 3'te enkesit ve boyut özellikleri ile esas alınan köprünün ilgili şartnameye uyum sağladığı Tablo 2'te gösterilmektedir. 


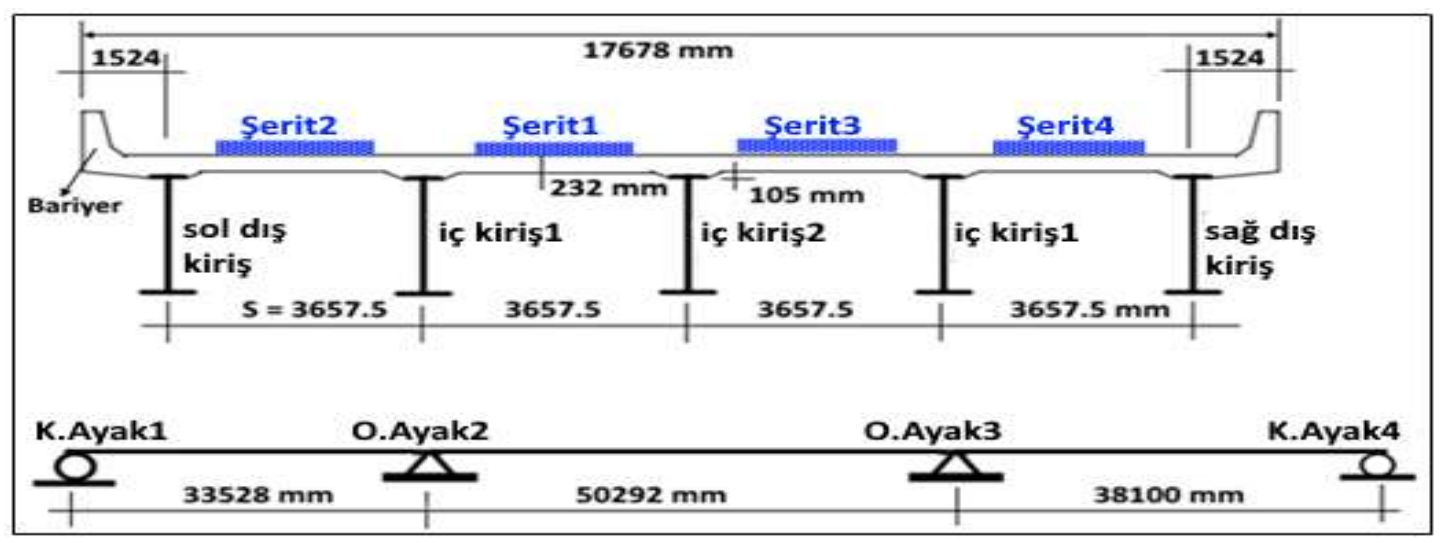

Şekil 3. Üç-açıklıklı 33-50-38 m köprünün en ve boy kesitleri

Tablo 2. AASHTO LRFD Şartnamesine göre sınırlamaların kontrolü

\begin{tabular}{|l|l|c|}
\hline \multicolumn{2}{|c|}{ AASHTO LRFD Şartnamesi } & Uygunluk \\
\hline Kiriş aralığı & $3.5 \mathrm{ft} \leq S=12 \mathrm{ft} \leq 16.0 \mathrm{ft}$ & + \\
\hline Kiriş açıklığ1 & $20 \mathrm{ft} \leq L=(110,165 \mathrm{ve} 125) \mathrm{ft} \leq 240$ & + \\
\hline Beton tabliye & $4.5 \mathrm{in} \leq t_{s}=9.125 \mathrm{in} \leq 12.0 \mathrm{in}$ & + \\
\hline Boyuna rijitlik parametresi & $10000 \mathrm{in}^{4} \leq K_{g}=3026490 \mathrm{in}^{4} \leq 7000000 \mathrm{in}^{4}$ & + \\
\hline Boyuna rijitlik parametresi & $10000 \mathrm{in}^{4} \leq K_{g}=3409396 \mathrm{in}^{4} \leq 7000000 \mathrm{in}^{4}$ & + \\
\hline Kiriş sayısı & $N_{b}=5>4$ & + \\
\hline
\end{tabular}

AASHTO LRFD şartnamesinin verdiği tüm sınırlamaların sağlanmış olması, LLDF hareketli yük dağıtma katsayılarının yükleri kirişlere tam anlamıyla yansıtacağını ve optimum tasarıma ulaşılacağını göstermektedir. Köprü hareketli yük katsayısı LLDF'nin hesaplanması ayrıntılı olarak Tablo 3'te gösterilmektedir.

Tablo 3. Üç-açıklıklı 33-50-38 m köprünün LLDF hareketli yük dağıtma katsayıları

\section{Açıklıklı 33-50-38 m Köprünün Hareketli Yük Dağıtma katsayılarının; LLDF Hesabı}

Hesaplarda kullanılan değerler, köprünün CSiBridge çözümünden aktarılmıştır. (Birim : Sı birim sistemi)

Köprüde kesit1 ve kesit2 ile nonprizmatik açıklıklar olduğundan, hesaplar açıklık ve mesnetler için ayrı ayrı yapılmıştır.

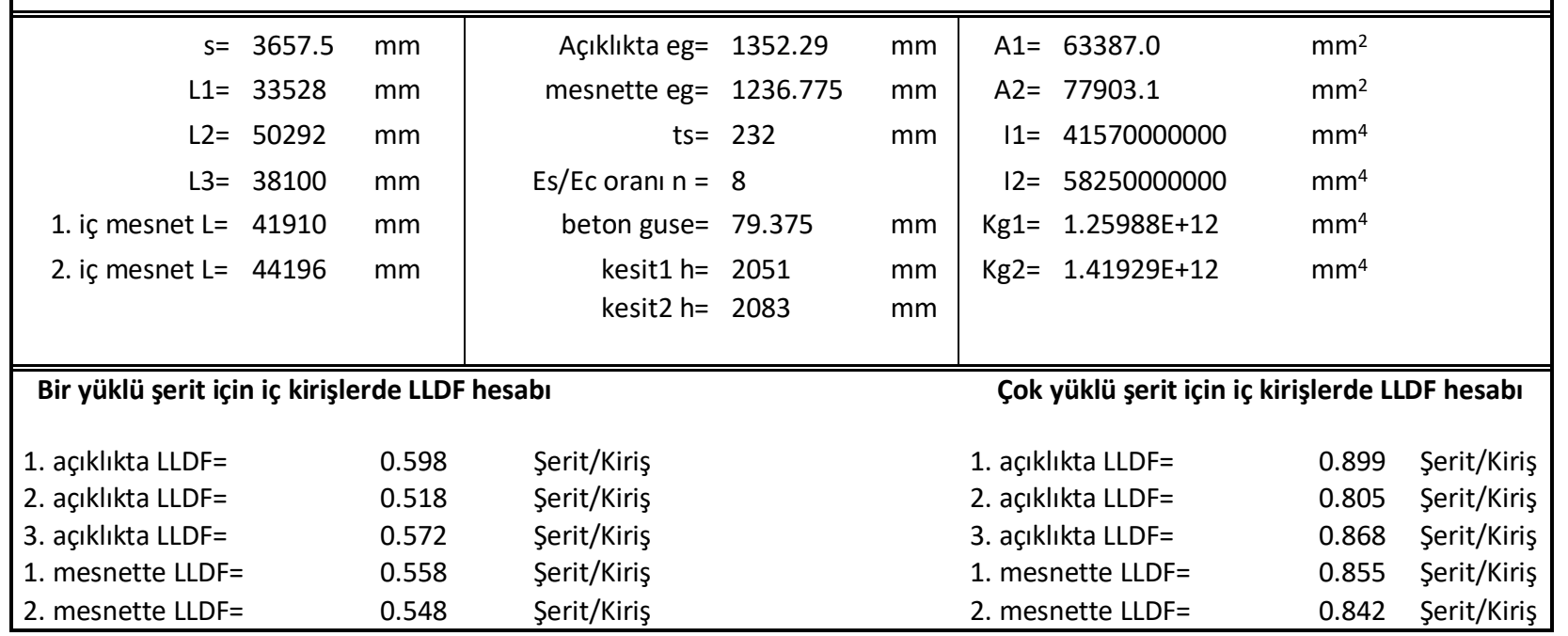


Şekil 3’te kesit özellikleri verilen üç açıklıklı 33-50-38 m açıklıklı köprü, SAP 2000 yazılımında modellenmiş, Çizgisel-Kiriş analiziyle en elverişsiz yükleme durumlarını elde etmek üzere aşağıdaki araç yük kombinasyonları uygulanmıştır:

$$
\begin{aligned}
& \text { Tandem }+ \text { Şerit } \rightarrow H L-93 M \\
& \text { Kamyon }+ \text { Şerit } \rightarrow H L-93 K \\
& (\text { Kamyon }- \text { Katar }) * 0.90+(\text { Şerit }) * 0.90 \rightarrow H L-93 S
\end{aligned}
$$

Araç hareketli yükleri altında elde edilen maksimumların maksimumu ZARF (envelope) momentleri Şekil 4’te gösterilmektedir.

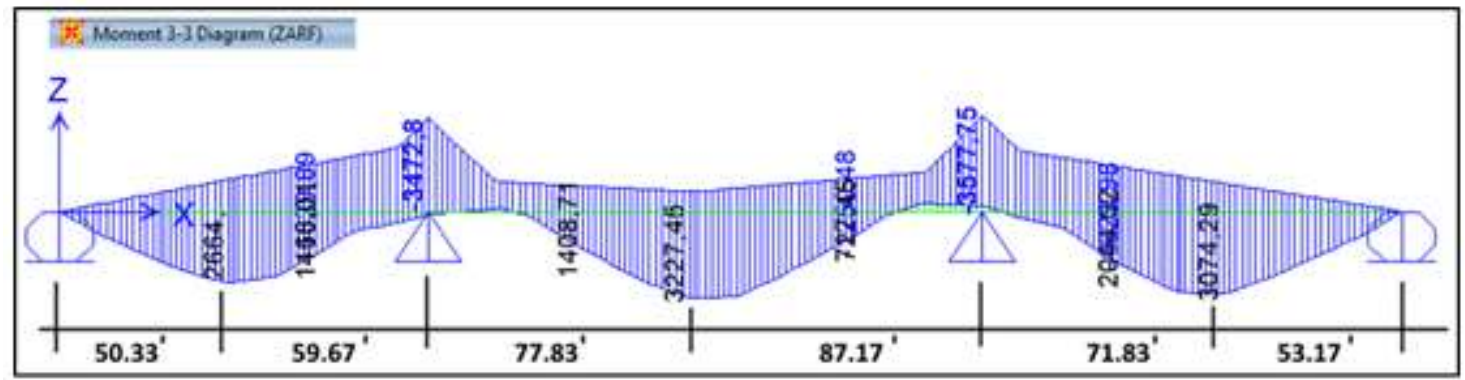

Şekil 4. Üç-açıklıkl1 33-50-38 m köprünün en elverişsiz yüklemeler altında moment değerleri

Çizgisel-Kiriş çözümünde araç yükü, hareketli yük dağıtma katsayısı LLDF ile çarpılmıştır. Birinci açıklıkta $L L D F=0.900$, ikinci açıklıkta $L L D F=0.805$, üçüncü açıklıta $L L D F=0.869$, birinci iç mesnette LLDF $=0.856$, ikinci iç mesnette LLDF $=0.843$ değerleri kullanılmıştır. Tasarımda göz önüne alınacak hareketli yük eğilme momentleri; en elverişsiz yüklemeler altında elde edilen Envelope (ZARF) momentlerinin, LLDF katsayısıyla çarpımı Eş. 7'de yer verilen ifade ile elde edilmektedir. Buna göre aşağıldaki sonuçlar elde edilmiştir (Burada kip-ft birim cinsinden olan momentler 1.35575 katsayısıyla kN.m’ye dönüştürülmüştür).

- $\quad \max M_{1}=1.35575 *(0.900 * 2664)=3250.55 \mathrm{KN} . \mathrm{m}$

- $\quad \max _{2}=1.35575 *(0.805 * 3227.45)=3522.37 \mathrm{KN} . \mathrm{m}$

- $\quad \max _{3}=1.35575 *(0.869 * 3074.29)=3621.96 \mathrm{KN} . \mathrm{m}$

- $\max \bar{M}_{1}=1.35575 *(0.856 * 3472.80)=-4030.26 \mathrm{KN} . \mathrm{m}$

- $\max \bar{M}_{2}=1.35575 *(0.843 * 3577.75)=-4089 \mathrm{KN} \cdot \mathrm{m}$

Çizgisel-Kiriş yöntemiyle analiz edilen üç açıklıklı bu köprü, CSiBridge, "Bridge Wizard" altında tasarlanarak (Şekil 5) tekrar analiz edilmiştir. Şekil 6' da gösterilen CSiBridge-3D kesin hesap sonuçları ile en elverişsiz yüklemeler altında Çizgisel-Kiriş çözüm yapılarak elde edilen sonuçlar açıklıklarda ve iç mesnetlerde karşılaştırıldığında hata oranları açıklıkta \% 4.33, mesnette \% 9.31 olduğu görülmüştür. Hata oranlarından anlaşılacağı gibi, Çizgisel-Kiriş yöntemiyle elde edilen sonuçların güvenli bir şekilde tasarımda kullanılabileceği anlaşılmıştır.

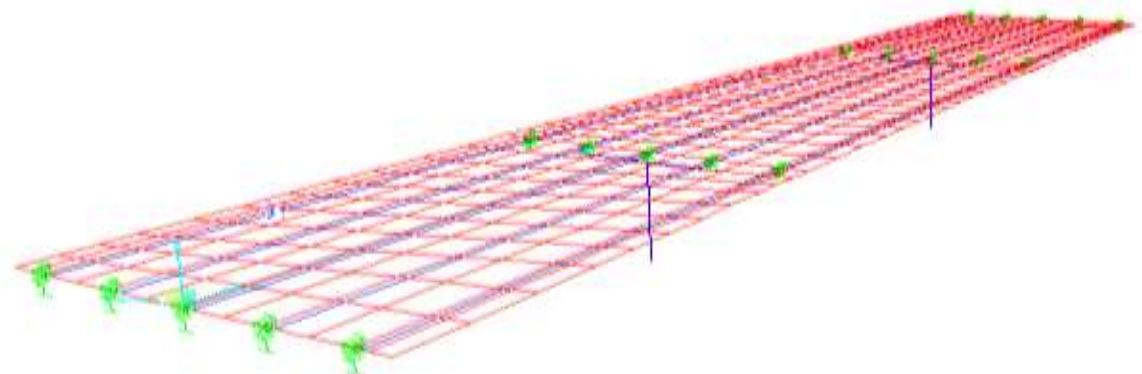

Şekil 5. Üç açıklıklı 33-50-38 m köprünün CSiBridge ile modellenmesi 


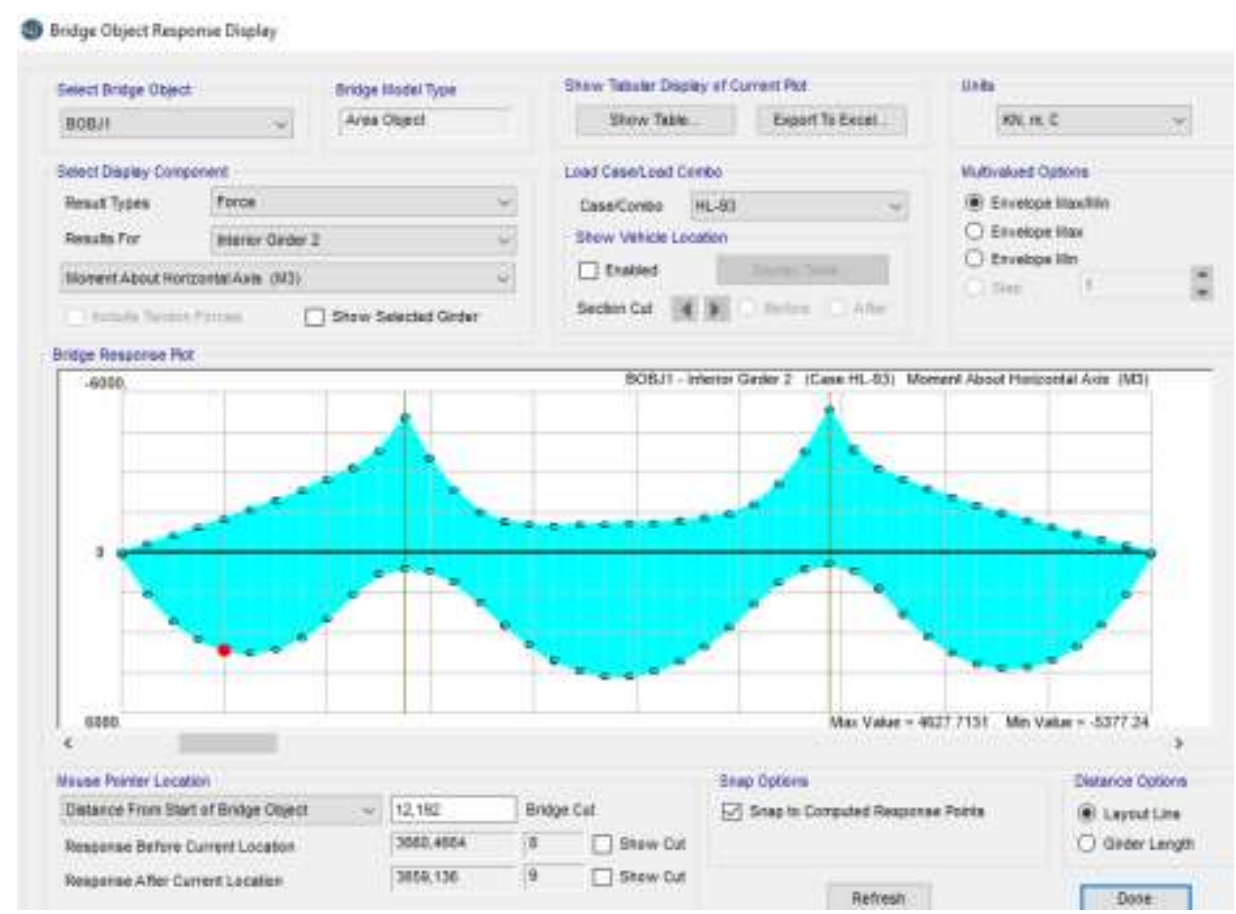

Şekil 6. HL-93 Araç Yüklemesinin CSiBridge ile Hesaplanan Hareketli Yük Momenti

\section{Sonuç ve Öneriler}

Bu çalışmada, köprülerin Çizgisel-Kiriş analiz yöntemi ve SAP2000-Bridge paket programları ile analizleri yapılarak elde edilen sonuçlar karşılaştırılmıștır. SAP2000-Bridge ile köprü çözümlerinde, program otomatik olarak araç hareketli yük dağıtma katsayılarıyla momentleri tüm kirişlere dağıtmaktadır. Bu özellik göz önüne alınarak köprülerde hareketli yük dağıtma katsayıları hesaplanmış ve Çizgisel-Kiriş analizden elde edilen momentlere yansıtılmışıır. Böylece, Çizgisel-Kiriş analiz yöntemiyle, SAP2000-Bridge çözümündeki moment değerlerine çok hassas bir şekilde yaklaşılmıştır. LLDF hareketli yük dağıtma katsayılarının geçerliliği bu çalışmada sunulan problemlerde, AASHTO LRFD şartnamesine göre kontrol edilerek, kullanılabilirliği gösterilmiştir. Bu ise, uygulamada kompozit çelik I-kiriş köprülerin en iyi tasarımı için gerçekçi bir yaklaşım olmuştur. Çizgisel-Kiriş analizlerde, en elverişsiz durumu göz önüne almak üzere, çok yüklü şerit durum LLDF hareketli yük dağıtma katsayılarının kullanılması 3D analizlere yaklaşımda belirleyici olmuştur. Böylece, AASHTO Köprü Şartnamesinde hesap ve uygulama özellikleri verilen LLDF katsayılarının güvenilirliği ortaya konulmuştur.

\section{Teşekkür}

Bu çalışma ilk yazarın biten doktora tezinin bir bölümünden türetilmiştir.

\section{Yazarların Katkısı}

Bu çalışma, Prof. Dr. Ragıp İNCE danışmanlığında Fatma ÜLKER PEKER tarafından hazırlanan doktora tez çalışmasından yapılmıştır.

\section{Çıkar Çatışması Beyanı}

Yazarlar arasında herhangi bir çıkar çatışması bulunmamaktadır.

\section{Araştırma ve Yayın Etiği Beyanı}

Yapılan çalışmada araştırma ve yayın etiğine uyulmuştur. 


\section{Kaynaklar}

[1] AASHTO LRFD Bridge Design Specifications, 6th ed. 2012. American Association of State Highway and Transportation Officials, Washington, DC.

[2] Peker F.Ü. 2019. Kompozit Çelik I-Kiriş Köprülerin Sezgisel Algoritma Teknikleriyle Optimum Tasarımı. Doktora Tezi, Fırat Üniversitesi, Fen Bilimleri Enstitüsü, Elazı̆̆.

[3] Zou B, Davalos J.F., Chen A., Ray I. 2010. Evaluation of Load Distribution Factor by Series Solution for Orthotropic Bridge Decks. Journal of Aerospace Engineering, 24 (2): 240-248.

[4] Dicleli M. and Erhan, S. 2008. Effect of Soil and Substructure Properties on Live-Load Distribution in İntegral Abutment Bridges. Journal of Bridge Engineering, 13(5): 527-539.

[5] Erhan S., Dicleli M. 2009. Live Load Distribution Equations for Integral Bridge Substructures. Engineering Structures, 31 (5): 1250-1264.

[6] Dicleli M., Erhan S. 2009. Live Load Distribution Formulas for Single-Span Prestressed Concrete Integral Abutment Bridge Girders. Journal of Bridge Engineering, 14 (6): 472-486.

[7] Erhan S., Dicleli M. 2009. Investigation of the Applicability of AASHTO LRFD Live Load Distribution Equations for Integral Bridge Substructures. Advances in Structural Engineering, 12 (4): 559-578.

[8] Dicleli M., Erhan S. 2010. Effect of Superstructure-Abutment Continuity on Live Load Distribution in Integral Abutment Bridge Girders. Structural Engineering and Mechanics, 34 (5): 635-662.

[9] Yalcin O.F., Dicleli M. 2013. Comparative Study on the Effect of Number of Girders on Live Load Distribution in Integral Abutment and Simply Supported Bridge Girders. Advances in Structural Engineering, 16 (6): 1011-1034.

[10] Yalcin O.F. 2017. A Comparative Study of Live Load Distribution in Skewed Integral and Simply Supported Bridges. KSCE Journal of Civil Engineering, 21 (3): 937-949.

[11] Kim Y.J., Tanovic R., Wight R.G. 2010. Load Configuration and Lateral Distribution of NATO Wheeled Military Trucks for Steel I-Girder Bridges. Journal of Bridge Engineering, 15 (6): 740 748.

[12] Fanous F., May J., Wipf T. 2010. Development of Live-Load Distribution Factors for GluedLaminated Timber Girder Bridges. Journal of Bridge Engineering, 16 (2): 179-187.

[13] Kalayc1 E., Civjan S.A., Breña S.F., Allen C.A. 2011. Load Testing and Modeling of Two Integral Abutment Bridges in Vermont, US. Structural Engineering International, 21 (2): 181-188.

[14] Hodson D.J., Barr P.J., Halling M.W. 2011. Live-Load Analysis of Posttensioned Box-Girder Bridges. Journal of Bridge Engineering, 17 (4): 644-651.

[15] Hodson D.J., Barr P.J., Pockels L. 2012. Live-Load Test Comparison and Load Ratings of a Posttensioned Box Girder Bridge. Journal of Performance of Constructed Facilities, 27 (5): 585593.

[16] Suksawang N., Nassif H., Su D. 2013. Verification of Shear Live-Load Distribution Factor Equations for I-Girder Bridges. KSCE Journal of Civil Engineering, 17 (3): 550-555.

[17] Mohseni I., Rashid A.K.A., Kang J. 2014. Effect of İntermediate Diaphragm on Lateral Load Distribution Factor of Multicell Box-Girder Bridges. KSCE Journal of Civil Engineering, 18 (7): 2128-2137.

[18] Mohseni I., Khalim A.R., Kang J. 2015. Live Load Distribution Factor at the Piers of Skewed Continuous Multicell Box Girder Bridges Subjected to Moving Loads. Transportation Research Record, 2522 (1): 59-69.

[19] Yan J., Deng L., He W. 2017. Evaluation of Existing Prestressed Concrete Bridges Considering The Randomness of Live Load Distribution Factor due to Random Vehicle Loading Position. Advances in Structural Engineering, 20 (5): 737-746.

[20] Thakuria P., Talukdar S. 2018. Live Load Distribution Factor in Precast I-Girder Bridge. In IOP Conference Series: Materials Science and Engineering, 431 (11): 112012

[21] Miranbeigi B., Maleki S. 2019. Live Load Distribution Factor for Tank Loading on Slab-Girder Bridges. KSCE Journal of Civil Engineering, 1-11.

[22] Choi W., Mohseni I., Park J., Kang, J. 2019. Development of Live Load Distribution Factor Equation for Concrete Multicell Box-Girder Bridges under Vehicle Loading. International Journal of Concrete Structures and Materials, 13 (1): 22. 